\title{
Movilidad y Circulación Política en Colombia 2006-2010
}

\author{
Luis Fernando Calvache Ceballos*
}

\begin{abstract}
Resumo
El presente artículo analiza la movilidad y circulación política en el Partido Conservador colombiano durante las elecciones parlamentarias de 2006 y 2010. Para ello, examina cómo se conformaron las listas según la medición de la concentración del liderazgo político y la circulación política en dicho partido. Aquí, se advierte la crisis del conservatismo a comienzos de los años 2000 y su posterior reconfiguración por medio de la renovación del liderazgo y las alianzas con otras fuerzas políticas.

Palabras claves: Partido conservador, partidos políticos, sistema electoral, circulación política, redes políticas.
\end{abstract}

\section{Introducción}

En Colombia, el debate alrededor del sistema partidista ha girado en torno a dos posiciones. La primera, infiere que no existe un sistema de partidos sino conglomerados o grupos políticos regionales (Losada, 2005), desde esta perspectiva un partido político es "cualquier grupo (...) que se presenta a competir en elecciones y que puede colocar mediante ellas a sus candidatos en cargos públicos" (Sartori, 1980, p. 82). La otra posición, reconoce la existencia de un sistema de partidos en estado de transición y consolidación (Roll, 2005).

La Reforma Política de 2003 buscó el fortalecimiento y cohesión de los partidos políticos por medio del cambio en las barreras electorales y la fórmula electoral, asimismo, intentó poner fin al número ilimitado de listas y a la fragmentación del sistema de partidos (Hoskin y Sánchez, 2006). Esta reforma propició en parte la modificación de las fuerzas inter e intrapartidistas, de hecho, en las últimas dos elecciones el parlamento presentó una renovación importante de sus integrantes. Los partidos políticos reaccionaron de diversas formas ante los cambios en la legislación, para algunos el reclutamiento de sus élites fue controlado por medio de los antiguos

\footnotetext{
* Profesor Tiempo Completo de la Corporación Universitaria Autónoma del Cauca, Colombia. Mestrando en la Universidad de Brasília (UnB) y Politólogo por la Universidad del Cauca, Colombia. Email: Ifcalvachec@gmail.com.
} 
líderes, pero en aquellos partidos con pugnas internas considerables se recurrió a la decisión del elector y al reconocimiento de la carrera política (Duque, 2011, p. 124).

El presente artículo analiza la movilidad y la circulación política en el Partido Conservador colombiano durante las elecciones parlamentarias de 2006 y 2010. Para ello, se estable el porcentaje de congresistas nuevos en la cámara y el senado en el periodo de estudio y se analiza la movilidad de los representantes políticos del conservatismo. Así mismo, se estudia la forma como el Partido Conservador definió sus listas y reclutó sus candidatos.

En la primera parte se presentan algunas consideraciones sobre la metodología de estudio. Luego, se expone el concepto de clase política y su relación con la noción de movilidad política. En un tercer momento, se presenta un breve análisis sobre los cambios sucedidos en la última década en el sistema electoral y de partidos en Colombia. Finalmente, se examina el comportamiento de la clase política en el Partido Conservador, con base en el porcentaje de congresistas nuevos y la concentración del liderazgo.

\section{Consideraciones metodológicas}

El presente texto busca examinar el grado de renovación o permanencia de la clase política institucionalizada en el Partido Conservador. Con este fin, se analizan tres factores del comportamiento político. En primer lugar, se observa el porcentaje de parlamentarios nuevos por cada elección así como los cambios en la filiación política de los candidatos, variable conocida como la circulación política. En el caso colombiano este hecho es relevante puesto que los políticos electos tienden a cambiar de partido político de una elección a otra. El porcentaje de circulación política (CP) es igual al número de elegidos nuevos por cien sobre el total de curules a repartir. Los rangos de circulación son: I) baja circulación entre $0-25 \%$ de nuevos miembros del congreso, II) circulación media, entre $26-50 \%$, III) alta circulación entre $51-75 \%$, y IV) muy alta circulación más del 75\% (Duque, 2008, p 5). 
En segundo lugar, se observa el grado de fragmentación política al interior del conservatismo por medio del índice de Número Efectivo de Candidatos (NECe) ${ }^{1}$, el cual señala el número real de candidatos que obtuvieron una votación considerable y excluye aquellos que se presentaron pero no obtuvieron votos significativos. Aquí se proponen dos rangos de clasificación (ver tabla No 1): el primero de ellos es la lista con predominio unipersonal y bipersonal, que acontece cuando en una lista abierta presentada por un partido, en nuestro caso el conservatismo, la votación se concentra en menos del $20 \%$ del total de candidatos en contienda. El segundo, es la lista multipersonal o unipersonal polarizada, que se presenta cuando la votación se concentra en más del $20 \%$ de los candidatos en contienda. Por ejemplo, en 2006 el Partido Conservador presentó 51 candidatos a las elecciones de senado, pero sólo 29.71 candidatos obtuvieron una votación considerable. Si se calcula el peso de esos 29.71 aspirantes sobre el total que es 51 , tenemos que el grado de fragmentación es de $58 \%$, lo que equivale a listas con predominio multipersonal o listas unipersonales polarizadas.

Tabla 1. Grados y Rangos del NECe.

\begin{tabular}{lr}
\hline \multicolumn{1}{c}{ Grado de Fragmentación } & Rango \\
Listas con predominio Unipersonal y & 0- $20 \%$ \\
Bipersonales & $\mathrm{NL}>20 \%$ \\
Listas Multipersonales y Listas & \\
Unipersonales polarizadas & \\
\hline $\begin{array}{l}\text { Fuente: Rangos propuestos por el autor con base en el índice NEC } \\
\text { 2012. }\end{array}$
\end{tabular}

Por último, se establece el grado de concentración del liderazgo político al interior del conservatismo. Los rangos que se han propuesto son: concentración alta, media y baja. La primera sucede cuando la decisión de las listas del partido descansa en la figura de la clase política y los candidatos. La segunda se presenta cuando la

\footnotetext{
${ }^{1}$ La fórmula del NECe, variante de la fórmula de Tageepera, expresa la proporción de votos o escaños que obtiene un determinado candidato por período electoral. Así, se obtiene la fragmentación al interior de los partidos. Así mismo, el Número Efectivo de Listas (NELe y NELp) expresa la proporción de escaños o votos que obtiene una lista en cada elección. Este índice permite entrever el nivel de fragmentación desde el punto de vista de las listas.
} 
definición de las listas depende de la clase política, los candidatos y los sufragantes. Por último, la concentración baja ocurre cuando la decisión sobre las listas en contienda es delegada al elector.

Tabla 2. Concentración del liderazgo.

\begin{tabular}{cc} 
Concentración del Liderazgo & Definición de listas \\
Alta (C) & Clase política (Candidatos) \\
Media (M) & Clase política (Candidatos) y Sufragantes. \\
Baja (D) & Sufragantes. \\
\hline
\end{tabular}

Fuente: Elaboración propia 2012

De este modo, se indaga ¿quién definió las listas al congreso?, ¿qué razones condicionaron dicha decisión? y ¿cómo se definieron? Si se compara el índice NECe y la concentración del liderazgo, se puede establecer si la competencia o triunfo electoral de los candidatos corresponde con su nivel de protagonismo en las decisiones.

En los partidos políticos es la clase política (candidatos) o los grupos de base los que se encargan de definir el orden y la lista de aspirantes finales. Al respecto, la clase política está en capacidad de incidir según el grado de participación al interior del partido, esta puede tomar una decisión unilateral o concertada mediante congresos, asambleas, encuestas o dejando la decisión en manos de los electores. Estos últimos cuentan con mecanismos de elección como el voto preferente.

A partir de estas tres variables, se entiende por movilidad política el proceso mediante el cual la clase política institucionalizada permanece, conforma sus candidaturas y reacciona ante los cambios del sistema electoral y de partidos. Dicha movilidad puede ser restringida, moderada y de apertura ${ }^{2}$. Para examinar la movilidad de la clase política institucionalizada se propone elaborar un análisis sobre las relaciones de poder al interior del conservatismo. Si bien es cierto, es posible ampliar

\footnotetext{
2 Restringida: personalización/ausencia de personalización más concentración alta/concentración media; moderada: personalización y concentración baja; de apertura: ausencia de personalización y concentración baja. Sin embargo, es necesario ahondar un poco más en la construcción de las variables, razón por la cual dicha clasificación no será tenida en cuenta en el presente texto.
} 
el espectro a otras fuerzas políticas, se insiste en el Partido Conservador toda vez que es una fuerza tradicional que afrontó recientemente un periodo de crisis y que ha procurado reconfigurarse en la última década, a pesar de la mencionada debacle de los partidos políticos en Colombia. En años recientes, se ha insistido en el impacto de la Reforma Política de 2003 en la reducción del número de partidos. Más allá de esta discusión, el presente trabajo toma la reforma como referencia, pero se centra principalmente en la acción de la clase política y sus diversas formas de afrontar los procesos electorales.

\section{Movilidad y circulación política en Colombia}

La noción de clase política procura establecer la relación entre el reclutamiento de los dirigentes políticos y su permanencia en el poder (Duque, 2008, p. 2). Para Gaetano Mosca, en todas las sociedades, sin importar su nivel de diferenciación, existen "dos clases de personas, una de los gobernantes y la otra de los gobernados" (Mosca, 1896). La clase política, goza de ciertos privilegios, realiza las funciones políticas y monopoliza el poder (Mosca, 1925). Para Michael Mann, la prevalencia de una minoría organizada sobre la mayoría se sustenta en el valor militar, la riqueza, las creencias religiosas, la cultura científica y la herencia (1993). Tanto el principio democrático como el carácter hereditario intervienen en la conformación de la clase política. Si bien, la elección por sufragio "parecería a primera vista estar en contradicción con la tendencia hacia la estabilidad de la clase política (...) los candidatos que tienen éxito en las elecciones democráticas casi siempre son aquellos de las fuerzas políticas que hemos ya enunciado y que con mucha frecuencia son hereditarias" (Mosca, 1986, p. 8).

A través del estudio de la clase política "podemos adentrarnos en la complejidad de algunas de las múltiples interacciones y dinámicas propias del sistema político" (Duque, 2008, p. 1). La clase política institucionalizada se refiere a aquellos actores que "participan de los privilegios del gobierno" ya sea porque se ubican en la cúspide de la esfera burocrática o "hacen parte del parlamento o de instancias locales de elección popular". A esta esfera pertenecen todos los políticos, incluso aquellos que 
se consideran "políticos de segunda fila". De este modo, la cooptación de este sector se da por medio de la pertenencia a un partido político y el "acceso a las instituciones a través de la elección popular (...) constituye la clase política electa, la clase política institucionalizada (Von Beyme 1993; Pasquino 2000, Duque, 2011, p. 122).

En este sentido, la clase política puede ser entendida como el referente de "aquellos personajes políticos que participan del gobierno, haciendo parte de los cuerpos colegiados o cargos uninominales como consecuencia de eventos electorales, teniendo como característica particular la presencia de estos actores en la administración estatal" (Roll, 2005, p. 117). Un análisis empírico de este tipo busca indagar ¿qué es y qué hace la clase política? (Von Beyme, 1995, p 11). La clase política también es entendida como "un cartel de las élites de los partidos; que aparece sobre todo debido al desarrollo del estado de partidos" (Von Beyme, 1995, p. 11).

\begin{abstract}
En un esquema cuyos polos corresponden, por una parte, a una absoluta estabilidad, en lo que se ha denominado puerta giratoria (revolving door), que expresaría la absoluta inmovilidad de la política que tiende a perpetuar los mismos círculos decidores y generaría una oligarquía parlamentaria y, por otra, a una total circulación, que expresaría la imposibilidad de conformación de una clase política profesional ante la continua entradasalida de los miembros de las instancias de representación, lo más frecuente es una situación de amalgama, una mezcla de casos de reelecciones y continuidad con casos de movilidad y renovación (Duque, 2008, p. 3).
\end{abstract}

En Colombia, los factores económicos, políticos, sociales y en los últimos años la vinculación ilegal entre grupos paramilitares y líderes políticos con interés de ascenso, han incidido en la renovación de la clase política institucionalizada. No sólo se conformaron nuevos partidos políticos como consecuencia de procesos de movilidad social, sino también la competencia intrapartidista permitió la promoción de nuevos sectores políticos. Los cambios presentados en la legislación electoral propiciaron la reducción del número de partidos políticos, una mayor cohesión y competencia partidista y en algunos casos mayor flexibilidad en la conformación de las listas. Por su parte, la lista única generó una competencia más fuerte entre los varones electorales que habían permanecido en el nivel oficial del partido y aquellos que se sumaron en 
elecciones posteriores. De hecho, la necesidad de superar el umbral permitió la conformación de coaliciones sin ningún tipo de horizonte ideológico.

Así mismo, surgieron nuevas fuerzas políticas que lograron cierta permanencia como el caso del Polo Democrático Alternativo y las coaliciones uribistas. Aún así, la falta de disciplina generó un mayor peso de las figuras carismáticas en la legitimidad del partido. Los partidos políticos han optado por figuras importantes para afianzar su capital electoral, lo que a su vez ha provocado un cambio en la organización de la competencia política y los liderazgos. Algunas colectividades han resuelto sus problemas de coordinación electoral con medidas como el voto preferente $y$, de hecho, en los últimos años tan sólo el Movimiento Independiente de Renovación Absoluta MIRA presentó listas cerradas en elecciones parlamentarias, lo que indica la falta de control de los dirigentes de otros partidos sobre los candidatos, pero también señala la búsqueda de votos por parte de algunas colectividades con el ánimo de superar el umbral y obtener mayor representación.

Al interior de los partidos la movilidad de la clase política obedece a factores como la carrera política, la postulación de candidatos, el nivel de organización de la competencia y la volatilidad del sufragio partidista. Además, el mérito desempeña un papel fundamental, por medio de procesos "democráticos, abiertos y competitivos". Cuando el liderazgo es personalista la renovación se relaciona con las redes de poder del aspirante, su posición frente a los líderes históricos y la posibilidad de conformación de partidos, facciones y fracciones políticas (Duque, 2011, p. 124).

\section{El sistema electoral y de partidos en Colombia}

El régimen electoral es el conjunto de elementos que regulan el transcurso de la elección del voto y que abarcan todos aquellos componentes que van desde el sufragio activo hasta la proclamación definitiva de los candidatos electos.

Todo sistema electoral genera un cierto grado de desproporcionalidad al ser aplicado a unos resultados electorales dados, entendiendo por ésta la diferencia entre el porcentaje de escaños que un partido recibe respecto del porcentaje de votos que logró en las elecciones (Lijphart, 1994, p. 57). Todo sistema electoral funciona como un filtro que criba o tamiza las manifestaciones que los ciudadanos han llevado a cabo en las urnas, al 
distribuir posteriormente los escaños entre los partidos contendientes (Ocaña y Oñate, 1999, p. 227).

Entre 1991 y 2002 el número de partidos políticos colombianos creció, debido al sistema de asignación de curules por residuo que propició la personalización de las listas y favoreció la constitución de microempresas electorales (Pizarro, 2002, p. 2). La proliferación de candidaturas se hizo cada vez más aguda y la disciplina partidista colapsó, ante el sistema de residuos que personalizó la composición de los movimientos políticos. La idea de propiciar partidos políticos con vocación nacional fracasó y los senadores continuaron siendo elegidos por las circunscripciones regionales. De igual forma, los partidos se fragmentaron aún más, ante la posibilidad de obtener mayores escaños por medio del sistema de residuos. A este respecto, Mainwaring expresa con claridad el panorama de los partidos políticos antes de la reforma de 2003:

Colombia tiene uno de los sistemas de partidos más singulares de todo el mundo. La singularidad se articula alrededor de dos factores. De una parte, los partidos se cuentan entre los más personalistas y atomizados en el mundo. Las organizaciones partidistas se han erosionado seriamente; el papel de los candidatos y políticos individuales es supremo (2002, p. 14).

La Reforma Política de 2003 intentó disminuir el número de fuerzas en competencia y procuró una mayor cohesión y disciplina partidista por medio del umbral, un nuevo método de asignación de escaños y la lista única (Rodríguez y Botero, 2006, p. 138-151).

\footnotetext{
Los resultados de la elección muestran claramente que los partidos y movimientos ganadores optaron en su mayoría por presentar listas abiertas. De los diez partidos que obtuvieron curules en el Senado, sólo uno se presentó con lista cerrada el Movimiento Mira, encabezado por Alexandra Moreno Piraquive. Este movimiento, el último de los que superaron el umbral del $2 \%$ en el Senado, ya había adoptado esta misma estrategia de disciplina estricta en las elecciones locales de octubre de 2003 (Rodríguez y Botero, 2006, p. 143).
}

Alrededor de movimientos políticos oficiales se aglutinaron una serie de aspirantes provenientes de fuerzas políticas con menores posibilidades. Por ello, en 
2006 el voto partidista fue menor que el voto por candidato, ante el mayor nivel de competencia entre los aspirantes que buscaban ganar sufragantes en procura de alcanzar el primer lugar de su facción. No obstante, el voto preferente "permitió resolver problemas de coordinación (...) La lista abierta evitaba este problema al dejar en manos de los votantes la decisión de determinar el orden en el que se entregarían las curules" (Rodríguez y Botero, 2006, p. 138-151).

Por otra parte, en el sistema de partidos colombiano "se presenta una situación de transición confusa" (Roll, 2005: 31). Si partimos de la idea según la cual los partidos políticos son confederaciones flexibles, tenemos que estos se organizan en tendencias, fracciones y facciones. Las primeras se entienden como un "conjunto estable de actitudes que se expresan en orientaciones ideológicas (...) con diversos grados de cohesión y de estabilidad en el tempo" (Duque, 2006, p. 174). Las fracciones son aquellas subunidades cohesionadas, organizadas y con un grado de estabilidad en el tiempo, "que realizan sus propios eventos, buscan recursos para sí mismas y no tanto para el partido y guardan una relación con el partido a manera de grupos cuasi soberanos" (Sartori, 1982; Harmel y Janda, 1994; Duque, 2006, p. 174). Por último, las facciones son grupos de poder que carecen de organización, son coyunturales y dependen de los liderazgos personalistas (Sartori, 1976; Duque, 2006, p. 174). En Colombia se presenta un sistema de partidos nacional y varios sistemas subnacionales que varían según la configuración política regional (Roll, 2005, p. 103).

La afirmación respecto a que el sistema político colombiano se caracteriza por tener un sistema de partidos bipartidista es una constante en los trabajos politológicos de muchos académicos (...). Sin embargo, aun aceptando tal afirmación, es necesario matizarla (...). En este sentido creemos que lo que hay que hacer es clasificarlos no por el número, sino por el tipo de competencia. Visto así, éste deja de ser bipartidista (Roll, 2005, p. 95).

Partiendo del enfoque expuesto por Panibianco (1990), según el cual existe al interior de los partidos dirigencias poliárquicas y oligárquicas, se intentará establecer la fuente del control político en el conservatismo. En ocasiones es la clase política o los sufragantes los que toman la decisión final sobre la preselección de los políticos electos. Por ello, "la dimensión de la fragmentación es, sin duda, una de las más 
importantes ya que nos informa acerca de la medida en la que el poder político se halla disperso o concentrado" (Ocaña y Oñate, 1999, p. 234).

Si bien es cierto, existen otros actores con incidencia en la toma de decisión sobre la elección final de los candidatos, aquí se excluyen de dicho proceso a los personajes pertenecientes a las élites políticas como es el caso de los gremios, asociaciones o actores políticos relevantes. Por esta razón, se parte de la idea que en la decisión final de los representantes políticos inciden de manera más directa los electores por medio del sufragio, y la clase política por medio de la definición de las reglas de juego, o ambos.

\section{Movilidad política en el Partido Conservador. Elecciones parlamentarias 2006-2010}

El nacimiento del Partido Conservador colombiano fue consecuencia del conflicto entre la iglesia católica y el Partido Liberal y producto de la "reacción de un sector de la sociedad que se opuso a las nuevas ideas y valores fundamentados en el liberalismo decimonónico" (Roll, 2005, p. 70). Después del Frente Nacional y luego de décadas de hegemonía de ambos partidos, el papel de los partidos tradicionales cambió, dada la aparición de nuevas fuerzas políticas y el fraccionamiento de estas agrupaciones.

Entre 1886 y 1930 se presentó el periodo conocido como la Hegemonía conservadora que fue interrumpido por la República Liberal (1930-1946). Nuevamente entre 1946 y 1953 el conservatismo dominó la escena política, pero luego del período de La Violencia y del pacto consociacional fue el Partido Liberal quien prácticamente controló la escena electoral desde 1974, tanto en las elecciones presidenciales como en la cámara y el senado (Roll, 2005, p. 79). 
Gráfica No 1. Porcentaje de curules en el senado y cámara de representantes. Partido Conservador 1994 - 2010.

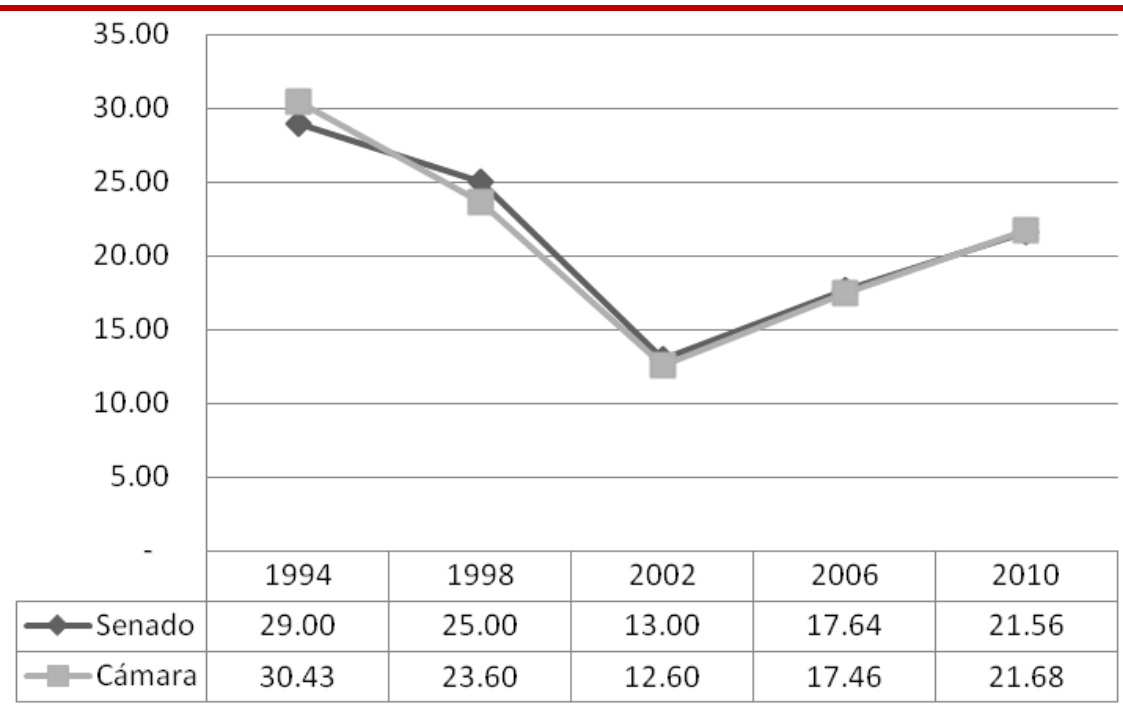

Fuente: Registraduría Nacional del Estado Civil. Cálculos propios 2011

Entre 1994 y 2002, el porcentaje de curules obtenidas por el conservatismo en el congreso descendió. En el caso de la cámara, la pérdida de capital electoral fue semejante, toda vez que el porcentaje de curules descendió a $12.60 \%$ en 2002 . Fue en este año, cuando algunos analistas coincidieron en la debacle conservadora que auguraba el fin del conservatismo. Sin embargo, el acercamiento del expresidente del partido Carlos Holguín Sardi a la campaña del uribismo permitió el repunté de las fuerzas conservadores.

Tabla No 3. NECe. Partido Conservador. Senado de la República. Colombia 20022010

\begin{tabular}{lrrr} 
NELp, NELe y NEL & 2002 & 2006 & 2010 \\
No de listas en contienda & 321 & 20 & 16 \\
NEL & 96.41 & 6.54 & 5.77 \\
No de partidos en contienda & 64 & 20 & 16 \\
Número de listas que obtienen curul & 102 & 12 & 10 \\
No de candidatos del Partido Conservador & 25 & 51 & 75 \\
NECe Partido Conservador & 15.68 & 29.71 & 32.27 \\
No Candidatos elegidos Partido Conservador & 13 & 18 & 22 \\
Total senadores & 102 & 102 & 102 \\
\hline
\end{tabular}

Fuente: Registraduría Nacional del Estado Civil. 2002-2010. Cálculos propios. 2012 
Desde 2002, el conservatismo ha comenzado lentamente a recuperar su caudal electoral y para 2010 su porcentaje de curules ya estaba por encima del $21.0 \%$. Si bien, no ha podido recuperar las curules que obtuvo en 1994, este repunte le permite una actuación importante en la resolución de la agenda del gobierno y la posibilidad de regresar a la presidencia.

Respecto a los tres últimos periodos electorales se advierte la reducción del número de partidos y listas en contienda, pero un incremento en la competencia intrapartidista, por lo menos en el caso del conservatismo, que se denota en el aumento del Número Efectivo de Candidatos que pasó de 15.68 en 2002 a 32.27 candidatos en 2010, lo que demuestra la inclusión de nuevos personajes políticos al partido con un caudal electoral importante.

\footnotetext{
Definir a los partidos como redes de poder, partes de un sistema de negociaciones e intercambios entre las distintas ramas del poder público, es fundamental para entender el funcionamiento del PC. A pesar de reconocer que este ha perdido poder tanto al nivel electoral como organizacional, es importante subrayar que esto no significa un detrimento automático de su poder. El PC sigue siendo fundamental en las alianzas electorales, tanto a nivel nacional como regional (Pachón, 2002, p. 87-88).
}

Ahora bien, en los comicios de 2002 se presentaron 321 listas a las elecciones de senado, pero sólo 96.41 listas tuvieron una participación importante. Para 2006, se redujo el número de listas en contienda a 20. De igual forma, se presentó una reducción en el número de partidos, que pasó de 64 en 2002 a 16 partidos en 2010. En el plano formal existió una mayor cohesión interpartidista y algunas facciones y fracciones lograron acomodarse en el interior de los sectores oficiales.

No obstante, a pesar de la reducción de la competencia interpartidista, en el conservatismo se presenta un aumento del número de fuerzas con preponderancia electoral. Por ejemplo, en 2002 el NEL fue de 96.41 listas pero el NECe fue de 15.68 candidatos, lo que significa que el comportamiento del NEL es indirectamente proporcional al desempeño del NECe. El crecimiento de éste último índice se explica por la llegada de nuevos líderes con un caudal electoral importante, que provenían de grupos ligados al conservatismo, quizá por esta razón en los últimos años el 
conservatismo ha tenido diversos problemas internos para actuar como un partido unificado.

Es importante resaltar que el conservatismo ha presentado históricamente conflictos de coordinación electoral entre el ámbito central y el regional. Este fenómeno converge con la falta de planificación sobre los relevos generacionales, luego del desgaste y desaparición de los grandes líderes de la colectividad. Desde la época del expresidente Andrés Pastrana, que si bien llegó al cargo sin el aval oficial de los conservadores, el partido no ha contado con liderazgos suficientes para aglutinar las diferentes fuerzas en disputa. Por ejemplo, en 2002 el partido decidió adherirse a la candidatura de Álvaro Uribe, puesto que no contaba con un candidato para el cargo de la Presidencia de la República. No obstante, la unión del partido con el uribismo le dio un nuevo aire a la colectividad y permitió su repunte.

\section{Concentración del liderazgo en el Partido Conservador 2006-2010}

Luego de la Reforma de 2003, algunas facciones conservadoras optaron por unirse a la coalición oficial, lo que generó no pocas disputas al interior del partido. En parte, tales problemas de coordinación electoral fueron resueltos mediante el voto preferente. Es difícil entrever que actores o líderes políticos fueron determinantes en la definición de la lista final en los comicios de 2006 y 2010. En el primer año, por ejemplo, el Partido Conservador depuró de su lista al candidato Héctor Julio Alfonso López hijo de la empresaria Enilce López, lo que produjo el retiro del presidente del Directorio Conservador de Bolívar Dairo Bustillo, situación que puso de manifiesto el intento por parte de la dirigencia central de controlar los avales regionales.

\footnotetext{
A partir de la elección popular de alcaldes y de la Constitución de 1991, el PC afronta varias realidades de carácter estructural y coyuntural: una organización central sin mucho poder, dos candidatos presidenciales derrotados y una nueva Constitución. Las funciones del directorio se han visto disminuidas, en parte debido a que el ordenamiento constitucional permitió la participación en elecciones de nuevos movimientos, al mismo tiempo que les otorgaba financiación (Pachón, 2002, p. 112).
}

En 2002, el conservatismo intentó cohesionar a sus diferentes grupos por medio de la consulta interna para elegir al candidato a la presidencia, este hecho 
representó el renacer de la colectividad. Sin embargo, durante el proceso de consulta fue clara la falta de disciplina del partido, por lo menos en el sometimiento a las decisiones de la mayoría conservadora, de hecho se presentó un supuesto ofrecimiento de la excandidata Noemí Sanín al senador conservador Julio Manzur para que no participara en la convención conservadora y declinara su apoyo al precandidato Juan Camilo Restrepo. (11 de enero, 2002). Definidas Alianzas Políticas. Diario El Tiempo, Colombia. Finalmente la convención eligió a Restrepo, pero la aspirante Noemí Sanín decidió presentar su candidatura por el Movimiento Independiente Sí Colombia, partido que ganó tan sólo una curul en el senado. A pesar de las 13 curules obtenidas por la fuerza conservadora en 2002, el expresidente de la colectividad Carlos Holguín Sardi amenazó con renunciar a su cargo ante el fracaso electoral en el departamento del Valle, lo que generó una nueva inestabilidad en el partido.

Aunque Juan Camilo Restrepo ganó la consulta interna, no contó con el apoyo suficiente para proseguir como aspirante conservador al cargo presidencial. Finalmente, Restrepo declinó su aspiración ante la división interna del conservatismo, tanto en el ámbito regional como nacional, dado que fueron primero los congresistas del departamento de Antioquia los que decidieron declinar su apoyo a este candidato y adherirse a la campaña de Uribe Vélez. Ante la renuncia de Restrepo y luego de un proceso largo de definición, los conservadores en cabeza de Carlos Holguín Sardi decidieron apoyar la candidatura de Álvaro Uribe Vélez. Sin embargo, el apoyo al candidato no fue en bloque, puesto que la decisión del conservador antipastrinista José Gregorio Hernández de apoyar la candidatura de Serpa generó dudas sobre la adhesión conservadora a Uribe. El apoyo a esta campaña generó diversas críticas por parte de líderes del conservatismo como Mario Ospina Hernández, quien denunció la falta de disciplina del partido (29 de mayo, 2002). Conservadores ayudamos. Diario El Tiempo, Colombia. Estos hechos ilustran no sólo la indisciplina del conservatismo sino también los diversos inconvenientes que ha tenido el partido para unificar las decisiones. 
Teniendo en cuenta la concentración del liderazgo, es posible afirmar que en 2006 la concentración del liderazgo fue media, dado que tanto dirigentes como sufragantes participaron en la definición final de las listas. Así, la votación más alta la tuvo la lista conservadora, por encima del líder tradicional Roberto Gerlein, de William Montes Molina y de Germán Villegas Villegas. Cabe resaltar, la superioridad del voto partidista sobre el de candidato, lo que demarca la preferencia de los sufragantes bien sea por el partido en general o la inconformidad con los candidatos finales.

En 2010, la coyuntura de las elecciones presidenciales generó de nuevo disidencias en el interior del conservatismo. De este modo, los liderazgos se dividieron entre los simpatizantes del uribismo y los seguidores de Juan Manuel Santos, de hecho un grupo numeroso de congresistas partidarios buscaron aproximarse a la campaña de Santos antes de la primera vuelta, incidente que se presentó luego de que Noemí Sanín ganara la consulta interna del conservatismo, obteniendo el aval como candidata presidencial del Partido Conservador.

En su momento, Sanín llamó la atención sobre la disidencia conservadora encabezada por el exministro Andrés Felipe Arias y afirmó que "si hay conservadores que se quieren ir para donde el doctor Juan Manuel Santos, que se vayan. La libertad es lo más importante". Pero, también se presentaron afirmaciones en favor de la campaña de Santos, por ejemplo Lucas Cañas, quien fue miembro del Directorio Nacional Conservador, mencionó la posibilidad del apoyo del conservatismo a la continuidad del gobierno de Uribe (22 de abril, 2010). Advertencia de Noemí a dirigentes según dijeron varios congresistas. Diario El Tiempo, Colombia.

Para 2010, al igual que en 2006, fueron varios los incidentes al interior de la colectividad y los intentos del conservatismo de unificar y cohesionar el partido. Sin embargo, nuevamente estos problemas de coordinación interna del Partido Conservador fueron resueltos por medio del voto preferencial. Sin duda, la campaña presidencial y la conformación de colaciones influyeron en la resolución final de las elecciones parlamentarias. En este sentido, la concentración del liderazgo fue media dado que tanto dirigentes como sufragantes participaron en la definición final de la lista conservadora. 


\section{Movilidad y circulación política en el Partido Conservador. Senado de la República 2006-2010}

En los últimos años, tanto la cámara como el senado asisten a un proceso de renovación de la clase política institucionalizada. En el caso del senado, la circulación política se ha mantenido alta, aunque se advierte un ascenso considerable en 2006 (72,12\%). En la cámara, el porcentaje CP fue medio en 2002 y 2006 y alto en 2010, este último crecimiento concuerda con el mismo comportamiento para el senado.

Gráfica No 2. Porcentaje de congresistas nuevos. Colombia. 2002-2006

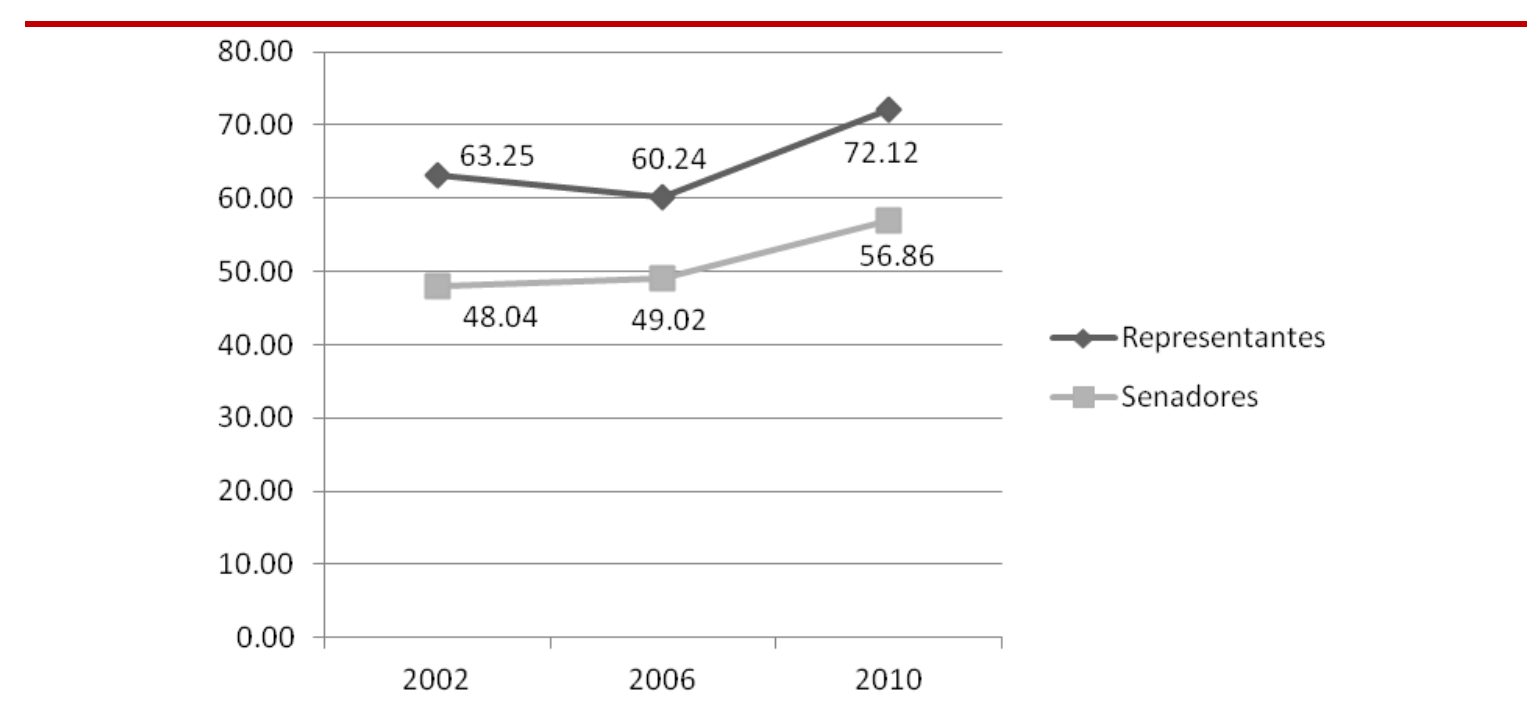

Fuente: Registraduría Nacional del Estado Civil. Cálculos propios.

Entre 2002 y 2010 se presentó una tenue renovación de liderazgos al interior del conservatismo. En los últimos años se percibe la emergencia de nuevos dirigentes, como Juan Manuel Corzo Román, Carlos Emiro Barriga, Germán Villegas Villegas, Carlos Eduardo Enríquez Maya y José Darío Salazar que provino del Movimiento Unionista y se adhirió al conservatismo oficial en las elecciones de 2002. Este panorama, quizá influya en la superación de la falta de relevo que se presentó en años anteriores, luego del desgaste de los grandes liderazgos.

La circulación política en el conservatismo no difiere del porcentaje nacional, de hecho se ha mantenido desde 2002. Cabe resaltar, que la renovación de los liderazgos 
ha permanecido estable y advierte el ascenso de algunos líderes que podrían desempeñar un papel importante a largo plazo, así como la emergencia de líderes regionales como José Darío Salazar. En este sentido, la circulación política contrasta con un alto grado de fragmentación en el conservatismo, en donde la lucha por llegar a lugares preponderantes de decisión se mantiene.

Tabla No 4. Movilidad y Circulación intrapartidista. Senado. Partido Conservador 1994-2010.

Candidato Elegido

Guillermo Cháves Cristancho Jorge Armando Mendieta Poveda Omar Yepes Alzate

Carlos Holguín Sardi

Francisco Javier Murgueitio Restrepo

Ciro Ramírez Pinzón

Carlos Salvador Albornoz Guerrero

Jesús Ángel Carrizosa Franco

Luis Humberto Gómez Gallo

Julio Alberto Manzur Abdala

Gabriel Ignacio Zapata Correa

Isabel Celis Yáñez

Jesús León Puello Chamie

Carlina Rodríguez Rodríguez

Consuelo de Mustafá

Hernán Francisco Andrade Serrano

Roberto Víctor Gerlein Echeverría

Efraín José Cepeda Sarabia

Juan Manuel Corzo Román

Carlos Eduardo Enríquez Maya

Jorge Hernando Pedraza Gutiérrez

José Darío Salazar Cruz

Germán Villegas Villegas

Carlos Emiro Barriga Peñaranda

William Alfonso Montes Medina

Alfonso Maria Núñez Lapeira

Iván Díaz Mateus

Ubeimar Delgado Blandón

Alirio Villamizar Afanador

Manuel Ramiro Velásquez Arroyave

José Iván Clavijo

Carlos Ramiro Chavarro

Luis Emilio Sierra Grajales

Fernando Eustacio Tamayo

Nora María García Burgos

Juan Mario Laserna

Juan de Jesús Córdoba Suárez

Juan Samy Meregh Marun

César Tulio Delgado Blandón

Olga Lucía Suárez Mira

$2002 \quad 2006 \quad 2010$

Co

PC PC

$P C$

$P C$

$P C$

$P C$

$P C$

$P C$

$P C$

EC

$P C$

$P C$

$P C$

PC

$P C$

$\mathrm{MN}$

MND

$\mathrm{MN}$

PC

PC PC

PC PC

MU PC $\quad P C$

$\begin{array}{ll}P C & P C \\ P C & P C\end{array}$

CC $P C$

MN

PC

$P C$

PC

$P C$

PC

MPD PC

PC

$P C$

$P C$

PC

PC

PC

PC

PC

PC

PC 
Liliana María Rendón Roldán

Myriam Alicia Paredes Aguirre

No de elegidos por partido

\% de Circulación CP Partido Conservador*
PC

13

18

22

$44.4 \quad 50.0$

PC: Partido Conservador; MND: Movimiento Nueva Fuerza Democrática; MN: Movimiento Nacional; MU: Movimiento Unionista; MPD: Movimiento Progresismo Democrático; SN: Movimiento de Salvación Nacional; Co: Coalición; EC: Equipo Colombia.

*La circulación CCP= No Elegidos nuevos*100/No Total Curules (desde 1978). Los grados de circulación son con cuatro, a saber: I) baja circulación entre $0-25 \%$ de nuevos miembros del congreso, II) circulación media, entre $26-50 \%$, III) alta circulación entre 51-75\%, y IV) muy alta circulación más del 75\% (DUQUE, 2011).

Es significativo resaltar, que dada la emergencia de nuevos liderazgos, algunos provenientes de sectores regionales, los acuerdos y decisiones se han visto afectadas, ante la falta de un liderazgo claro y aglutinador. De hecho, la concentración del liderazgo muestra como en los últimos años el conservatismo ha optado por el voto preferente. En esta recomposición de los liderazgos incidirá el caudal electoral, la permanencia y la reconfiguración de las alianzas, si bien, se advierte un tenue reconocimiento de nuevos líderes regionales, es importante tener en cuenta el nuevo rol que puede desempeñar el capital político regional en la conformación de las alianzas nacionales.

\section{Consideraciones finales}

En un primer momento, se advierte la complejidad a la hora de determinar la forma como se llega a la decisión final sobre los candidatos parlamentarios al interior de los partidos. Aquí se propuso un análisis inicial sobre tal definición a partir de la dicotomía sufragantes - dirigentes. Sin embargo, ello amerita el examen de los hechos presentes al interior de cada grupo, más allá de la simple definición de que grupo influyó o no en la decisión sobre las listas.

En un segundo momento, es importante considerar la división que se presenta en el conservatismo. En el plano formal el conservatismo aparece como una fuerza 
unificada, pero ello no significa que exista una cohesión real, dado que la pugna entre líderes establecidos y marginados es evidente.

Respecto a la fragmentación del liderazgo, cabe resaltar que el conservatismo presentó listas multipersonales, en parte porque la unificación permitió la entrada de disidentes tradicionalmente conservadores, como el Movimiento de Salvación Nacional, el Movimiento de Salvación y del Movimiento Unionista. Por ello, la pugna interna creció y los problemas de coordinación se tornaron más complejos. De igual forma, un análisis de este tipo es importante para considerar cómo reaccionan los viejos liderazgos al interior de un partido y las estrategias de los nuevos líderes para acomodarse a las reglas de juego.

\section{Referencias}

Bartolini, S. et. al. 1996. Manual de Ciencia Política. Alianza Editorial. S. A. Madrid, España.

Botero, F y Rodríguez, J. C. 2008. Ceticismo otimista: a reforma eleitoral colombiana de 2003. In: Santander Ugo, Carlos. Freire Penteado, Nelson. Os procesos eleitorais na América Latina (2005-2006). L.G.E Editora. Brasilia.

Cox, G. 1999. Electoral rules and electoral coordination. In: Annual Review of Political Science, v. 2.

Duque, Javier. 2006. Partidos divididos, dirigencia fragmentada. Los partidos Liberal y Conservador colombianos 1974-2006. In: Convergencia - Revista de Ciencias Sociales. UAEM, México, N.41, mayo-agosto, pp.173-209.

Duque, Javier. 2008. Políticos y partidos. La circulación de la clase política institucionalizada en Colombia 1958-2006. Ponencia presentada en el 1er Congreso Colombiano de Ciencia Política, Bogotá, septiembre 30-octubre 3.

Duque, Javier. 2011. El congreso de la República en Colombia. Estabilidad y renovación en las elecciones de 2010. In: Colombia Internacional, 74, pp 119-151.

Gerald, R y Zapata, J. 2000. Sistema electoral y de partidos en Colombia: propuestas de reforma. Fedesarrollo. Bogotá, Colombia.

Gutiérrez Sanín, F. et al. 2002. Degradación o cambio: evolución del sistema político colombiano. Editorial Norma. Bogotá, Colombia.

Hoskin, G y Sánchez, M. 2006. La Reforma Política de 2003. ¿La salvación de los partidos políticos colombianos? Ediciones Uniandes. Bogotá, Colombia. 
Leal Buitrago, F y Dávila, A. 1990. Clientelismo: el sistema político y su expresión regional. Tercer mundo editores. Bogotá, Colombia.

Mosca, G. 2002. La clase Política. Selección de Norberto Bobbio. Fondo de Cultura Económica. México.

Mosca, G. 1925. Teorica dei governi e governo parlamentare, studi storici e sociali. Istituto Editoriale Scientifico. 301 páginas.

Mann, M. 1993. Las sociedades como redes organizadas de poder, In: Mann, M. Las Fuentes del poder social. Vol I, Alianza Editorial, Madrid.

Nohlen, D. 2009. La Democracia Instituciones, conceptos y contexto. Universidad Javeriana. Bogotá.

Ortega, C. 2011. Representación política y sistemas electorales. Curso Cuatrimestral Universidad de Granada, España.

Ocaña, F y Oñate, P. 1999. Índices del sistema electoral y del sistema de partidos. Una propuesta informática para su cálculo. Reis 86/99.

Pizarro Leongómez, E. 2002. La atomización partidista en Colombia: el fenómeno de las microempresas electorales. Biblioteca Luis Ángel Arango. Bogotá, Colombia.

Rodríguez, J C y Botero, F. 2006. Ordenando el caos. Elecciones legislativas y reforma electoral en Colombia. In: Revista de Ciencia Política. Volumen 26 No 1.

Roll, D. 1999. Inestabilidad y continuismo en la dinámica del cambio político en Colombia. Editorial ICFES, Bogotá, p. 30.

Roll, D. 2005. Partidos políticos y Congreso: elites políticas y mayorías parlamentarias en Colombia en la década de los noventa. Universidad Nacional de Colombia.

Roll, D. 2001. Un siglo de ambigüedad: Para entender cien años de crisis y reformas políticas en Colombia. Cerec. Bogotá.

Sartori, G. 1980. Partidos y sistemas de partidos. Madrid Alianza, Tomo I, p. 92.

Von Beyme, K. 1995. La clase política en el estado de Partidos. Alianza editorial. Madrid, España.

Wills Otero, L. 2009. ¿Juntos pero no revueltos? Partidos, candidatos y campañas en las elecciones legislativas de 2006, In: Botero, Felipe (compilador). Universidad de los Andes. Universidad de los Andes. Facultad de Ciencias Sociales - Ceso. Departamento de Ciencia Política.

Wills Otero, L. 2009. El sistema político colombiano: Las reformas electorales de 1991 y 2003 y la capacidad de adaptación de los partidos. Universidad de los Andes. Bogotá, Colombia.

\section{WEBGRAFÍA}


www.registraduríanacionaldelestadocivil.gov.co

$\underline{\text { www.andes.cvisible.edu.co }}$

\title{
TEXTOS DE PRENSA
}

"Definidas Alianzas Políticas" [Redacción política] (11 de enero, 2002). Diario El Tiempo, Colombia. Consultado el 9 de agosto de 2013 en:

http://www.eltiempo.com/archivo/documento/MAM-1363014

"Conservadores ayudamos" [Redacción política] (29 de mayo, 2002). Diario El Tiempo, Colombia. Consultado el 19 de julio de 2013 en:

http://www.eltiempo.com/archivo/documento/MAM-1313124

"Advertencia de Noemí a dirigentes según dijeron varios Congresistas". (22 de abril, 2010). Diario El Tiempo, Colombia. Consultado el 15 de junio de 2013 en:

http://www.eltiempo.com/archivo/documento/MAM-3934554

\section{Agradecimientos}

Agradezco a Karen Ordóñez y Sandra Tejada, estudiantes de Ciencia Política de la Universidad del Cauca, quienes colaboraron con la recolección de la información.

\begin{abstract}
Mobility and political movement in Colombia 2006-2010

The following article analyzes the mobility and political circulation of the Colombian Conservative Party during the parliamentary elections of 2006 and 2010. In order to allow this analysis, it is presented an evaluation of how the lists were formed based on the concentration measurement of the political leadership and on the circulation of the mentioned political party. It will be pointed that there is a crisis of the conservatism during the 2000s and its reconfiguration afterwards, through the leadership renovation and the alliances with other political bodies.
\end{abstract}

Key-words: Conservative party, political parties, electoral system, political circulation, political networks 